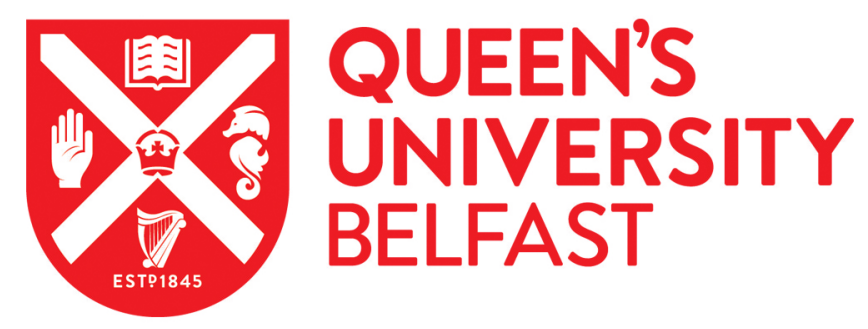

\title{
What, Where and When? Using Google Trends and Google to investigate patient needs and inform Pharmacy Practice
}

Hanna, A., \& Hanna, L-A. (2019). What, Where and When? Using Google Trends and Google to investigate patient needs and inform Pharmacy Practice. International Journal of Pharmacy Practice, 27(1), 80-87. https://doi.org/10.1111/ijpp.12445

Published in:

International Journal of Pharmacy Practice

Document Version:

Peer reviewed version

Queen's University Belfast - Research Portal:

Link to publication record in Queen's University Belfast Research Portal

Publisher rights

(c) 2018 Royal Pharmaceutical Society. This work is made available online in accordance with the publisher's policies. Please refer to any applicable terms of use of the publisher.

\section{General rights}

Copyright for the publications made accessible via the Queen's University Belfast Research Portal is retained by the author(s) and / or other copyright owners and it is a condition of accessing these publications that users recognise and abide by the legal requirements associated with these rights.

Take down policy

The Research Portal is Queen's institutional repository that provides access to Queen's research output. Every effort has been made to ensure that content in the Research Portal does not infringe any person's rights, or applicable UK laws. If you discover content in the Research Portal that you believe breaches copyright or violates any law, please contact openaccess@qub.ac.uk. 


\section{What, Where and When? Using Google Trends and Google to investigate Patient Needs and inform Pharmacy Practice}

Alan J. Hanna and Lezley-Anne Hanna

Queen’s University Belfast

\section{Objectives}

The aim was to provide a comprehensive overview (using pertinent examples) of the various ways that Google Trends and Google data could inform pharmacy practice. The objectives were to: examine what type of information people search for in relation to a common class of medicines; ascertain where people are directed to (websites) following an initial search for a medicine or medical condition; and establish information about when they search.

\section{Methods}

The methodology differed depending on whether Google Trends or Google was being interrogated but the search domain was always limited to the United Kingdom. Google Trends was queried, typically for a five-year time frame, and data downloaded for many search inputs relating to medical conditions (self-treatable and non-self-treatable) and medicines (bought over-the-counter and prescribed). Google was queried and data collected for searches related to "antibiotics".

\section{Key findings}

Google Trends revealed a previously unknown seasonality pattern for irritable bowel syndrome. Related searches for "antibiotics" revealed a high level of interest in the appropriateness of concomitant alcohol consumption and queries about what antibiotics are. Largely, people were being directed to reputable websites following their initial search input about a prescription-only medicine. However, searches for over-the-counter medicines were more likely to lead to commercial domains. 


\section{Conclusions}

This is one of the first studies to investigate use of Google Trends and Google in a pharmacyspecific context. It is relevant for practice as it could inform marketing strategies, public health policy and help tailor patient advice and counselling.

\section{Keywords}

Community Pharmacy, Use of Internet as Information Source, Patient Behaviour, Antibiotics 


\section{What, Where and When? Using Google Trends and Google to investigate patient needs and inform Pharmacy Practice}

\section{Introduction}

Internet search data has the potential to provide valuable insights into population behaviour. One tool that allows users to interact with internet search data is Google Trends, a publicly available online resource, provided by Google Inc. For nominated query terms, it provides insights into the timing, frequency and geographic source of matching Google searches. ${ }^{1}$

Google Trends has been used for various purposes such as ascertaining trends of substance and illegal drug use and forecasting associated premature deaths, ${ }^{2,3}$ exploring awareness about medical conditions, ${ }^{4}$ and for surveillance and prediction of infectious diseases such as influenza and Dengue Fever. ${ }^{5-8}$ Additionally, other experts have used Google to examine mental health issues such as suicide likelihood, ${ }^{9}$ assess the quality of patient information and guidance available on the internet, ${ }^{10}$ to detect internet search activity for particular conditions ${ }^{11}$ and the impact of public health campaigns. ${ }^{12}$

The aim of this work was to provide a comprehensive overview (using pertinent examples) of the various ways that Google and Google Trends data can inform pharmacy practice. To the best of our knowledge this is the first such study. The objectives (which can be considered in terms of 'what', 'where' and 'when') were to:

- examine what information people search for in relation to medication and medical conditions

Relevance: helps to identify gaps in knowledge and understanding and better inform patient advice and counselling. 
- ascertain where people are directed to (websites) when they search for particular medicines or conditions

Relevance: once this has been identified, targeted work can be undertaken to ensure the public are getting reliable health information after they perform an initial search.

- investigate when people are searching and determine whether seasonality patterns exist Relevance: this can help with the timing of health promotion campaigns and stock management.

\section{Methods}

The methodology and search strategy is outlined under the terms 'what', 'where' and 'when' (aligning with the objectives) using specific examples for each.

What information people search for in relation to particular medication and medical conditions.

Specific example: using Google Trends for antibiotics to glean information about related searches.

Search strategy: on October 8, 2017, Google Trends was queried and data collected for related searches following the search inputs: "antibiotics"; "amoxicillin"; "flucloxacillin"; "trimethoprim"; "doxycycline"; "nitrofurantoin"; "clarithromycin"; "penicillin". The specific antibiotics were those appearing in the 'Top 100 prescriptions dispensed in the community by community pharmacists, appliance contractors and dispensing doctors in England in $2015{ }^{\prime}{ }^{13}$ The United Kingdom domain was chosen, from January 1, 2012 to December 31, 2016 (data over a five year period), using the "all query categories" (the default setting). For each search input, Google Trends returns the top 25 'related queries'. These were recorded and thematic analysis undertaken. Antibiotics were chosen as the example as they are a commonly 
prescribed and familiar class of medicines yet have received worldwide media attention in the last few years about the prevalence and consequences of antimicrobial resistance due to inappropriate use. ${ }^{14}$

Where people are directed to (websites) when they type particular medicines or medical conditions into the Google search bar.

Specific examples: these focussed on where people are being directed to in relation to dispensed medicines, over-the-counter brands, self-treatable and non-self-treatable conditions. Search strategy: a list was compiled from the 'Top 100 prescriptions dispensed in the community by community pharmacists, appliance contractors and dispensing doctors in England in 2015 ${ }^{13}$ Each term was entered into a Google search on $23^{\text {rd }}$ September 2017, within the United Kingdom domain. For each set of search results, the first ten unique domain names were extracted and assigned a rank based on their page position, from 1 (first search result, highest rank) to 10 (lowest rank). Searches returning multiple pages from the same domain were treated as a single result. A similar approach was taken to compile a list of overthe-counter products which was derived from the Pharmaceutical Journal's published list of the top 50 brands. ${ }^{15}$ For conditions, this list was developed with reference to the British National Formulary (BNF) chapters ${ }^{16}$ and divided into self-treatable conditions $(n=74)$ and non-self-treatable conditions $(\mathrm{n}=76)$. Medical terms were converted into plain language as these were considered to be more likely search terms. For example, menorrhagia was replaced by "heavy periods" and dysmenorrhoea was replaced by "period pain".

Substitutions of terms from the list were justified for two reasons. Firstly, to avoid using medical terms that were likely to be unfamiliar to the lay person. Here Google Trends was used to find more frequently queried related terms. Secondly, to filter terms with ambiguous 
meanings (e.g. cold and corn) that would have provided non-medical results. Further details, and the list of conditions are available in the online Supplemental material.

\section{When people are searching}

Example: using Google Trends to ascertain whether interest in a particular medical condition (irritable bowel syndrome) and a social/lifestyle factor (smoking cessation) followed a seasonality pattern.

Search strategy: On October 9, 2017, Google Trends was queried and data downloaded for the following search inputs: ["ibs" + "irritable bowel syndrome"; "quitting smoking" + "stopping smoking" + "giving up cigarettes"]. We searched within the United Kingdom domain from 2004-2016 (the largest possible range of full calendar years) using the "all query categories" (the default setting). We selected irritable bowel syndrome as one example of a recurrent selftreatable condition that healthcare professionals may not instantly associate with having a seasonal pattern (i.e. conditions such as the common cold, flu and hay fever were avoided as their seasonality pattern is established and well documented in pharmacy practice textbooks $\left.{ }^{17,18}\right)$. Smoking cessation was chosen as there is a fixed month each year in the United Kingdom for a public health campaign ${ }^{19}$ and therefore one could hypothesize that Google search interest would be greatest around the time of this. Google Trends provide 'interest over time' measured on a relative scale from $0-100$, with peak popularity coinciding with a value of 100. A value of 50 means it was receiving half the level of peak interest. Monthly observations are returned for search periods spanning greater than 5 years. A seasonal-trend decomposition procedure was applied to extract the trend and monthly seasonality pattern for the last five complete calendar years. $^{20}$

Ethical approval was not required as this work used freely available, non-identifiable, Google data only and did not involve animals or human volunteers. 


\section{Results}

What information people search for in relation to particular medicines

From the Google Trends analysis, five main themes were identified. These related to:

- specific infections (i.e. urinary tract infection, chest, skin, throat, chlamydia, malaria, toothache)

- concomitant consumption of alcohol

- $\quad$ side-effects

- administration and dosage

- what is an antibiotic and how does it work

Where people are directed to (websites) when they type particular medicines or medical conditions into the Google search bar.

Table 1 indicates the top ten most commonly returned domains for the top 100 prescribed medicines list ${ }^{13}$ and top 50 OTC product list ${ }^{15}$. In each case, the count indicates the number of times the website domain appears near the top of the search results (i.e. within the first ten unique domains). The average rank (i.e. ordinal position) is also listed. A low rank indicates that when the domain appears in the top ten, it is near the top of the search results. The table therefore indicates the pervasiveness and prominence of each site across the searches.

As can be seen Google searches for prescription-only medicines most commonly returned Drugs.com, Wikipedia, electronic Medicines Compendium, WebMD and BNF. However, Google searches for OTC medicines most commonly returned Chemist Direct, Wikipedia, Superdrug, Boots and Amazon.

Similarly, Table 2 indicates the top ten most commonly returned domains for the non-selftreatable and self-treatable conditions list. ${ }^{16}$ As can be seen Google searches for non-self- 
treatable conditions most commonly returned NHS, Wikipedia, WebMD, Boots and Healthline Media Inc. However, Google searches for self-treatable conditions most commonly returned NHS, Wikipedia, Boots, WebMD, and Healthline Media Inc.

Place holder: Insert Tables 1 and 2 here please.

\section{When}

Figure 1 shows the seasonality pattern relating to irritable bowel syndrome and Figure 2 shows the seasonality pattern for smoking cessation. As can be seen, interest in irritable bowel syndrome varies about $20 \%$ annually, falling from a high point in August to its lowest level in December. The single largest change occurs between December and January. With regard to smoking cessation, a larger annual variation of about $45 \%$ was evident. January shows the largest interest, and December the lowest, (although a second wave of interest from August to October is observed).

Place holder: Insert Figure 1 around here please.

Place holder: Insert Figure 2 around here please. 


\section{Discussion}

The work has provided useful baseline data about the type of information that can be gleaned from Google Trends and Google, in a pharmacy practice context. For example, a self-treatable condition (irritable bowel syndrome) was found to exhibit annual seasonality. Additionally, queries related to "antibiotics" appeared to suggest a lack of knowledge about this class of medicine and its concomitant use with alcohol. Differences were also apparent between searches for prescription-only and OTC medicines, with OTC searches more commonly linked to commercial domains.

In relation to strengths and weaknesses: to the best of our knowledge, this is the first such study to investigate use of Google Trends and Google from a pharmacy practice standpoint. We consider that this paper provides a useful proof of concept about the type of information that can be derived and utilised in practice. The UK was chosen as the search domain because we reside and work in the UK. Initial consideration was given to using the 'worldwide search' function but we quickly realised that unless search terms were included in multiple languages, the results would be biased towards English-speaking countries. We did not have the expertise to do this, particularly regarding the lay terms that patients would use when searching, and some of the material was not relevant in a worldwide context anyway (such as prescriptiononly deregulations and national health promotion campaigns). Moreover, this should not cause a significant problem in terms of transferability, as other pharmacists can select the country/region applicable to them as part of their search methodology. Additionally, while it is also possible to perform inter-regional comparisons, this was not particularly fruitful in our examples as smaller regions of the UK (such as Northern Ireland) yielded inadequate data for any reports to be generated. Furthermore, it is possible that we had incomplete retrieval of data due to our search strategy (the search terms chosen). Finally, it can be difficult to draw absolute 
conclusions from Google Trends data alone and therefore results need to be interpreted with caution.

Regarding 'what' (the related searches for the 'antibiotics' query), it is noteworthy that searches commonly ask 'what is/are antibiotics?' which shows that people may not understand what antibiotics are, or how they work. This is perhaps surprising considering how often they are prescribed (or at least were in the past) and have been the subject of media campaigns. More work is required to ensure this fundamental question is addressed as part of antimicrobial stewardship campaigns and at the point of care. It is encouraging to see that the conditions being searched for are those where antibiotics are typically advocated such as a urinary tract infection and a chest infection rather than viral infections like the common cold. Similarly, other key findings (related searches) were how antibiotics should be taken and whether alcohol was safe to consume alongside antibiotics. It would be helpful for pharmacists to be more proactive about including information about this during antibiotic counselling to ensure they are meeting patient needs and avoiding unnecessary risks. Currently, the focus tends to be about avoidance in the context of antibiotics such as metronidazole, due to the risk of a disulfiramlike reaction. ${ }^{21}$ While advice about interactions is paramount to patient safety, an explicit discussion about the absence of interactions with food, alcohol or other medicines may provide patients with important reassurance and possibly help their understanding and adherence to medicines.

In terms of 'where', with the current drive for greater self-care ${ }^{22}$ and increased prevalence of internet use $\mathrm{e}^{23}$, it is crucial that people are routinely directed towards reliable online information. It is encouraging to see that some of the websites that people are being directed to, after typing a particular medical condition into the Google search bar, are reputable, authoritative sources of information, frequently with government backing [for example, the British National Health 
Service (NHS)]. It is noted that several of the resources are US-based which has implications for UK residents, for example, product availability, doses, directions and licensed indications may differ. Wikipedia represents a potential exception ${ }^{24}$. There was little difference between the self-treatable and non-self-treatable condition websites. Perhaps it was more interesting to note the variation in websites for prescription-only versus OTC medicines. When people searched for prescription-only medicines using Google, they tended to be directed to several trustworthy domains such as electronic Medicines Compendium, WebMD, BNF, Patient and NHS (see Table 1). However, when people searched for OTC medicines using Google, the websites tended to be commercial (Chemist Direct, Superdrug and Boots) with some having no healthcare or pharmacy expertise (Amazon and Morrisons). It would be useful if authoritative resources that provide information on prescription-only medicines included guidance on OTC products too.

Ascertaining 'when' people were searching over a particular timeframe was insightful; the examples we selected both revealed seasonality patterns. Irritable bowel syndrome exhibited a modest swing in interest of around $20 \%$ over the year, peaking in August, and falling steadily to its lowest level in December. The single largest change occurs between December and January. In comparison, smoking cessation exhibited a large swing of around 45\%. Interest peaked in January and dipped in December (however there was a second wave of interest from August to October). It is unsurprising that the peak time is at the start of a new year when resolutions are being set however, it is somewhat curious that the second peak in interest did not correlate with the UK National No Smoking Day (March). ${ }^{19}$ As previously mentioned, it is important to have an awareness of online searching patterns so that launches of marketing strategies, public health policies and health promotion campaigns can be informed by these. It would be useful to ascertain whether this peak level of interest mirrors OTC medicine sales 
and prescribing trends. Google Trends should also be used to assess the impact of campaigns and the level of interest in deregulated prescription-only products from the time of their launch onto the OTC market.

\section{Conclusion}

Google Trends and Google enable free, easily accessible, insights into human behaviour which can consequently inform practice alongside other data. To the best of our knowledge this is first such study to comprehensively investigate the use of Google Trends and Google from a pharmacy practice standpoint. The examples outlined in this paper should provide some helpful baseline findings and provoke thought as to the type of information that can be derived and utilised.

\section{Funding}

This research received no specific grant from any funding agency in the public, commercial, or not-for-profit sectors.

\section{Conflicts of Interest}

The authors declare that they have no conflicts of interest to disclose. 


\section{References}

1. Google Trends (2017). Available at: https://trends.google.co.uk/trends/ (accessed $3^{\text {rd }}$ October 2017). Archived at http://www.webcitation.org/6u7Ci2LMr (10th October 2017).

2. Yin S, Ho M. Monitoring a toxicological outbreak using Internet search query data. Clin Toxicol (Phila). 2012; 50(9): 818-822.

3. Parker J, Cuthbertson C, Loveridge S, Skidmore M, Dyar W. Forecasting state-level premature deaths from alcohol, drugs, and suicides using Google Trends data. J Affect Disord. 2017; 213: 9-15.

4. Shin HT et al. Relative high interest in acne on the internet: a web-based comparison using google trends. Ann Dermatol. 2014; 26(5): 641-642.

5. Ginsberg J et al. Detecting influenza epidemics using search engine query data. Nature. 2009;457(7232):1012-1014.

6. Gluskin RT et al. Evaluation of Internet-based dengue query data: Google Dengue Trends. PLoS Negl Trop Dis. 2014; 8(2): e2713.

7. Milinovich GJ et al. Internet-based surveillance systems for monitoring emerging infectious diseases. Lancet Infect Dis. 2014; 14(2): 160-168.

8. Nuti SV et al. The use of google trends in health care research: a systematic review. PLoS One. 2014; 9(10): e109583.

9. Ma-Kellams $\mathrm{C}$ et al. Rethinking suicide surveillance: Google search data and selfreported suicidality differentially estimate completed suicide risk. Clin Psychol Sci. 2016;4(3):480-484.

10. Martin A et al. A systematic assessment of Google search queries and readability of online gynecologic oncology patient education materials. Gynecol Oncol. 2017; 147(1): 206. 
11. Murray $\mathrm{G}$ et al. Detecting internet search activity for mouth cancer in Ireland. Br J Oral Maxillofac Surg. 2016; 54(2): 163-165.

12. Ling R, Lee J. Disease monitoring and health campaign evaluation using Google search activities for HIV and AIDS, stroke, colorectal cancer, and marijuana use in Canada: a retrospective observational study. JMIR Public Health Surveill. 2016; 2(2): e156.

13. Prescribing and Medicines Team Health and Social Care Information Centre. Prescriptions Dispensed in the Community England 2005-2015 (2016). Available at: http://content.digital.nhs.uk/searchcatalogue?productid=20895 $\quad$ (accessed 3rd October 2017). Archived at http://www.webcitation.org/6u7DjhlqF (10th October 2017).

14. World Health Organization (WHO). Global action plan on antimicrobial resistance, 2015. Available at: http://www.who.int/antimicrobial-resistance/publications/globalaction-plan/en/ (accessed 3rd October 2017). Archived at http://www.webcitation.org/6u7DsNohB (10th October 2017).

15. The OTC market in Britain in 2015, Top 50 brands. Pharm J. 2016; 296(1): 7887.

16. Joint Formulary Committee. British National Formulary, $73^{\text {rd }}$ edn. London: BMJ Group and Pharmaceutical Press, 2017.

17. Blenkinsopp A, Paxton P, Blenkinsopp J. Symptoms in the Pharmacy - a Guide to the Management of Common Illnesses, $7^{\text {th }}$ edn. Chichester: Wiley Blackwell, 2014.

18. Rutter P. Community Pharmacy Symptoms, Diagnosis and Treatment, $4^{\text {th }}$ edn. London: Elsevier, 2017.

19. Awareness UK. National No-Smoking day (2017). Available at: https://www.awarenessdays.com/awareness-days-calendar/no-smoking-day-2017-0309/ (accessed 4th October 2017). Archived at http://www.webcitation.org/6u7EGGw7S (10th October 2017). 
20. Cleveland RB et al. STL: A seasonal-trend decomposition procedure based on loess. J Off Stat. 1990; 6(1): 3 .

21. Electronic Medicines Compendium. Metronidazole $400 \mathrm{mg}$ Tablets Summary of $\begin{array}{llll}\text { Product } & \text { Characteristics } & \text { (2017). Available }\end{array}$ https://www.medicines.org.uk/emc/medicine/23050 (accessed 4th October 2017). Archived at http://www.webcitation.org/6u7EnaUJD (10th October 2017).

22. Department of Health, GOV.UK. How can we all reap the benefits of self-care? (2016) Available at: https://socialcare.blog.gov.uk/2016/08/24/how-can-we-all-reap-thebenefits-of-self-care/ (accessed 4th October 2017). Archived at http://www.webcitation.org/6u7EyRINt (10th October 2017).

23. The Office of Communications (Ofcom). Adults' media use and attitudes report (2017). Available at: https://www.ofcom.org.uk/_data/assets/pdf_file/0020/102755/adults-

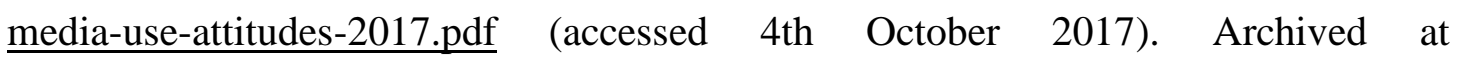
http://www.webcitation.org/archive.php (10th October 2017).

24. Kupferberg N, Protus BM. Accuracy and completeness of drug information in Wikipedia: an assessment. J Med Libr Assoc, 2011; 99(4): 310-313. 
Table 1 Where people are directed to (top 10 websites) when they type particular medicines into Google search bar

\section{Prescribed Medicine List}

\section{OTC Medicine List}

\begin{tabular}{|c|c|c|c|c|c|}
\hline \multirow[b]{2}{*}{ Website domain } & \multicolumn{2}{|c|}{ Average } & & \multicolumn{2}{|c|}{ Average } \\
\hline & Count & Rank & Website domain & Count & Rank \\
\hline Drugs.com (US) & & & Chemist Direct (UK) & & \\
\hline www.drugs.com & 86 & 2.70 & www.chemistdirect.co.uk & 29 & 5.52 \\
\hline Wikipedia & & & Wikipedia & & \\
\hline en.wikipedia.org & 84 & 4.20 & en.wikipedia.org & 28 & 4.21 \\
\hline Electronic Medicines & & & & & \\
\hline Compendium (UK) & & & Superdrug (UK) & & \\
\hline $\begin{array}{l}\text { www.medicines.org.uk } \\
\text { WebMD (US) }\end{array}$ & 82 & 4.07 & $\begin{array}{l}\text { www.superdrug.com } \\
\text { Boots (UK) }\end{array}$ & 28 & 5.64 \\
\hline www.webmd.com & 67 & 4.41 & www.boots.com & 25 & 3.28 \\
\hline British National & & & & & \\
\hline Formulary, accessed via & & & & & \\
\hline National Institute for & & & & & \\
\hline Health and Care & & & & & \\
\hline Excellence (UK) & & & Amazon (UK) & & \\
\hline bnf.nice.org.uk & 49 & 6.02 & www.amazon.co.uk & 23 & 4.83 \\
\hline Healthline Media Inc. & & & Electronic Medicines & & \\
\hline (US) & & & Compendium (UK) & & \\
\hline www.healthline.com & 40 & 4.50 & www.medicines.org.uk & 22 & 6.41 \\
\hline NetDoctor (UK) & & & NetDoctor (UK) & & \\
\hline www.netdoctor.co.uk & 40 & 5.98 & www.netdoctor.co.uk & 17 & 5.47 \\
\hline Patient (UK) & & & Tesco (UK) & & \\
\hline patient.info & 39 & 5.95 & www.tesco.com & 15 & 6.27 \\
\hline $\begin{array}{l}\text { National Health Service } \\
\text { (UK) }\end{array}$ & & & Morrisons (UK) & & \\
\hline www.nhs.uk & 36 & 2.69 & groceries.morrisons.com & 12 & 6.92 \\
\hline RxList (US) & & & Sainsburys (UK) & & \\
\hline www.rxlist.com & 29 & 5.52 & www.sainsburys.co.uk & 12 & 8.17 \\
\hline
\end{tabular}

The left hand side shows the top ten most commonly returned domains for the top 100 prescribed medicines list; the right hand side relates to the top 50 OTC medicines list. Count indicates the number of times the website domain appears near the top of the search results (i.e. within the first ten unique domains). The average rank (i.e. ordinal position) is also listed. A low rank indicates that when the domain appears in the top ten, it is near the top of the search results. 
Table 2 Where people are directed to (top 10 websites) when they type particular medical conditions into Google search bar

Non-self-treatable conditions

\begin{tabular}{l} 
Website domain and \\
name of organisation \\
\hline National Health Service \\
(UK) \\
www.nhs.uk \\
Wikipedia \\
en.wikipedia.org \\
WebMD (US) \\
www.webmd.com \\
Boots (UK) \\
www.webmd.boots.com \\
Healthline Media Inc. \\
(US) \\
www.healthline.com \\
MedicineNet (US) \\
www.medicinenet.com \\
Bupa (UK) \\
www.bupa.co.uk \\
Daily Express (UK) \\
www.express.co.uk \\
NetDoctor (UK) \\
www.netdoctor.co.uk \\
MedlinePlus (US) \\
medlineplus.gov
\end{tabular}

Count

Average

Rank

Website domain and name

Self-treatable conditions

of organisation

National Health Service

(UK)

$\begin{array}{ll}71 & 2.27 \\ 63 & 4.56\end{array}$

www.nhs.uk

72

Wikipedia

en.wikipedia.org

47

4.06

Boots (UK) in partnership

with WebMD

$36 \quad 5.67$

www.webmd.boots.com

45

WebMD (US)

$31 \quad 5.90$

www.webmd.com

Healthline Media Inc. (US)

$21 \quad 5.00$

www.healthline.com

MedicineNet (US)

$19 \quad 5.95$

www.medicinenet.com

NetDoctor (UK)

$17 \quad 6.29$

www.netdoctor.co.uk

Mayo Clinic (US)

$16 \quad 6.44$

www.mayoclinic.org

Medical News Today (UK)

www.medicalnewstoday.co

$16 \quad 7.56$

$\mathrm{m}$

Bupa (UK)

$14 \quad 4.79 \quad$ www.bupa.co.uk

The left hand side shows the top ten most commonly returned domains for the non-selftreatable conditions $(n=76)$; the right hand side relates to self-treatable conditions $(n=74)$.

Count indicates the number of times the website domain appears near the top of the search results (i.e. within the first ten unique domains). The average rank (i.e. ordinal position) is also listed. A low rank indicates that when the domain appears in the top ten, it is near the top of the search results. 

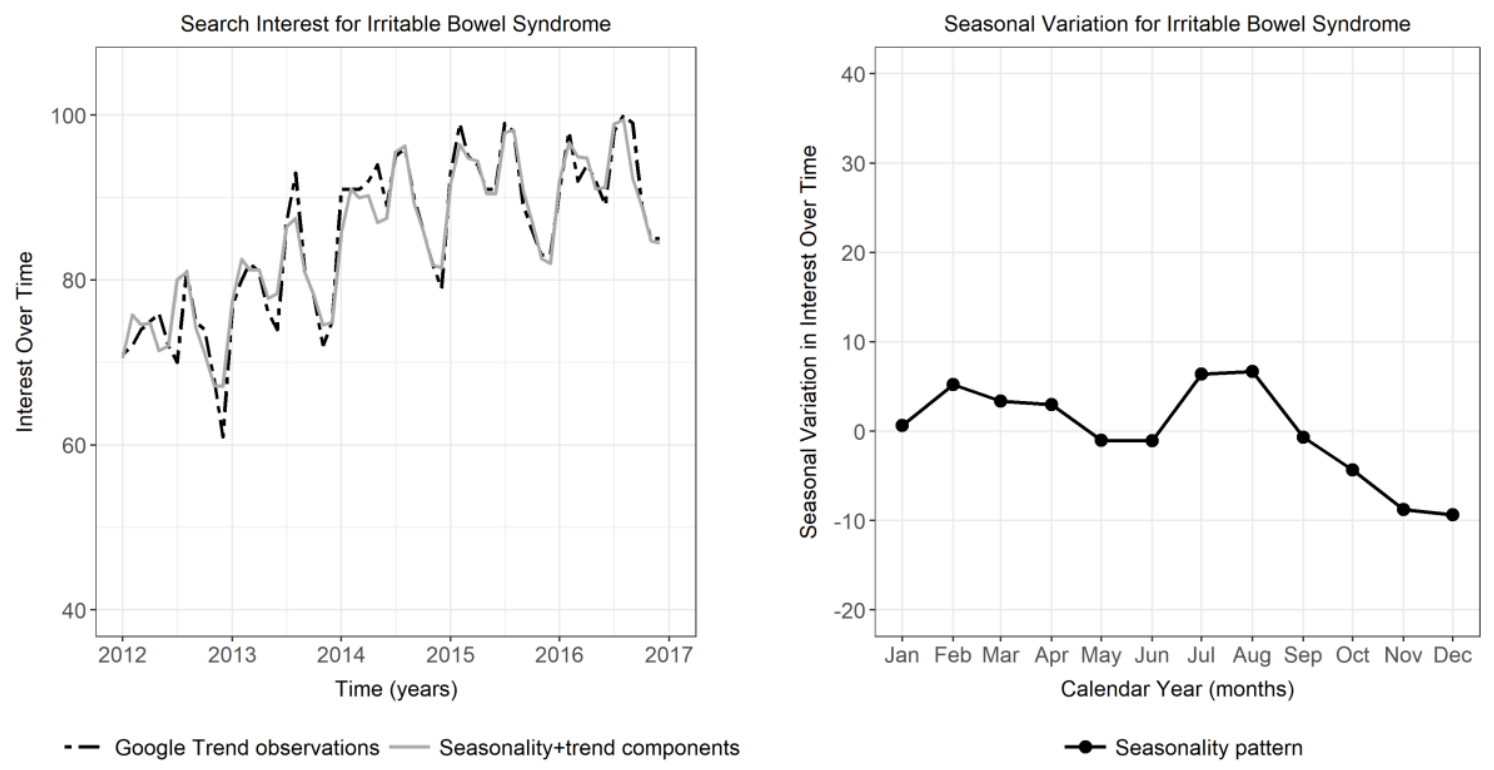

Figure 1 - Search interest and fitted seasonality pattern for Irritable Bowel Syndrome. Search interest obtained from Google Trends has been linearly decomposed into seasonality, trend and irregular components using the standard technique 'Seasonal Decomposition of Time Series by Loess (STL)'.21 The left hand side depicts the observed search interest for five complete calendar years (dotted line), and the combined seasonality and trend components (solid line). The right hand side depicts the recurring seasonality pattern plotted over a single twelve month period.
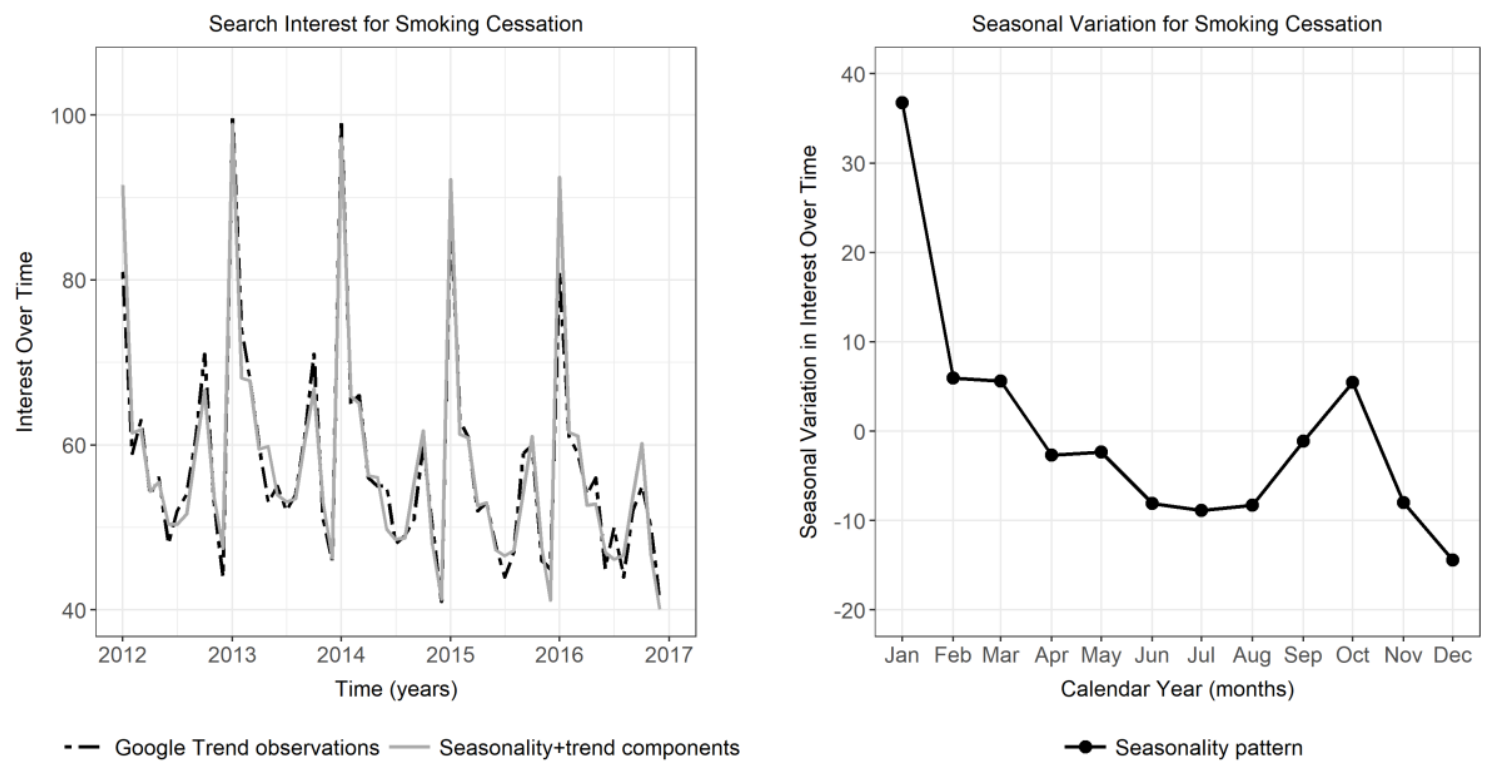

Figure 2 - Search interest and fitted seasonality pattern for Smoking Cessation. The decomposition approach is the same as described in Figure 1. The left hand side depicts the observed search interest for five complete calendar years (dotted line), and the combined seasonality and trend components (solid line). The right hand side depicts the recurring seasonality pattern plotted over a single twelve month period. 